\title{
Evaluation of Cells and Medium Optimization for Invitro Model of Diabetic and Electrolyte Imbalance
}

\author{
Alfino Sebastian ${ }^{1}$, Widya Wasityastuti ${ }^{2 *}$, Dwi Aris Nugrahaningsih ${ }^{3}$, Hevi Wihadmadyatami ${ }^{4}$, Tutik Sri Wahyuni $^{5}$, and \\ Tety Hartatik $^{6}$ \\ ${ }^{1}$ Laboratory of Genetical Engineering, Research Center for Biotechnology, Universitas Gadjah Mada, Yogyakarta, Indonesia \\ ${ }^{2}$ Department of Physiology, Faculty of Medicine, Public Health and Nursing, Universitas Gadjah Mada, Yogyakarta, Indonesia \\ ${ }^{3}$ Department of Pharmacology and Therapy, Faculty of Medicine, Public Health and Nursing, Universitas Gadjah Mada, Yogyakarta, \\ Indonesia \\ ${ }^{4}$ Department of Anatomy, Faculty of Veterinary Medicine, Universitas Gadjah Mada, Yogyakarta, Indonesia \\ ${ }^{5}$ Department of Pharmaceutical Science, Faculty of Pharmacy, University of Airlangga, Surabaya, Indonesia; and Natural Product \\ Medicine Research and Development, Institute Tropical Disease, University of Airlangga, Surabaya, Indonesia \\ ${ }^{6}$ Department of Animal Breeding and Reproduction, Faculty of Animal Science, Universitas Gadjah Mada, Yogyakarta, Indonesia
}

\begin{abstract}
Metabolism syndrome has many negative impacts on human health. Various efforts and methods are attempted in the treatment of this disease. One of the methods used is CRISPR/Cas9 gene therapy. Retesting of knock out cells using the CRISPR/Cas9 method is needed to evaluate its success. In conducting the test, the right medium is needed so that the results are optimal and can be evaluated properly. In this study, we optimized the medium for three types of cells (fibroblasts, myoblasts and macrophages) in high and low glucose medium to evaluate gene knockout results. The medium was modified by adding high concentrations of glucose and sodium. The results, in macrophage culture, giving variations in glucose concentration in low glucose medium gave a significantly different percentage of live cells between treatments, while the treatment with variations in glucose concentration in macrophages in high glucose medium and fibroblasts and myoblasts in high and low glucose medium did not show any difference in the percentage of living cells. In the treatment of various concentrations of natrium, macrophages, fibroblasts and myoblasts on high and low glucose medium all showed significantly different percentages of living cells. Therefore, DMEM low glucose medium is suitable as a medium for the treatment of high glucose and natrium induction in macrophage cells, but is not suitable for fibroblast and myoblast cells.

Keywords: Medium, Optimization, Fibroblast, Myoblast, Macrophage.
\end{abstract}

\section{INTRODUCTION}

Metabolic syndrome is a collection of symptoms of abnormalities in a person who has at least three of five medical conditions, such as obesity, hypertension, high blood glucose levels, high serum triglyceride levels, and low high density lipoprotein. Metabolic syndrome not only occurs in adulthood, but also at a young age which is associated with the risk of developing cardiovascular disease and type 2 diabetes [1][2]. In the United States, approximately $25 \%$ of the adult population has the metabolic syndrome, and the proportion increases with age, especially among racial and ethnic minorities. Metabolic syndrome has a negative impact on an increase of 5 times the risk of type 2 diabetes mellitus, 2 times the risk of cardiovascular disease [2], 2-4 times the risk of stroke, 3-4 times the risk of stroke heart or myocardial infarction, even increase the risk of death 2 times greater [1].

In general, the metabolic syndrome originates from environmental factors, lifestyle such as excessive carbohydrate consumption and lack of physical activity that leads to a series of abnormal metabolic events. Insulin resistance, metabolic syndrome, and prediabetes are closely related to each other and have overlapping aspects. This syndrome is thought to be caused by an underlying disorder of energy utilization and storage. Many efforts have been made to treat patients with metabolic syndrome, such as implementing a healthy lifestyle. Weight loss program and regular diet by reducing calorie intake by 500-1000 calories/day, reducing saturated fat, cholesterol, and sodium intake, and implementing physical activity 30-60 minutes/day. The increasing risk of death caused by metabolic syndrome, encourages researchers in the health sector to develop treatment with molecular therapy approaches or gene therapy.

Gene therapy is a therapeutic technique used to correct mutant (abnormal/defective) genes that are responsible for the occurrence of a disease. Initially, gene therapy was created to treat hereditary (genetic) diseases that occur due to mutations in one gene, such as cystic fibrosis [3]. Gene therapy later developed to treat diseases that occur due to mutations in many genes, such as cancer. In addition to inserting normal genes into mutant cells,

*Coresponding Author: wasityastuti@ugm.ac.id 
other gene therapy mechanisms that can be used are homologous recombination to eliminate abnormal genes with normal genes, prevent abnormal gene expression through gene attenuation techniques, and perform selective reverse mutations so that abnormal genes can function normally again [4].

Handling of patients with metabolic syndrome can also be done through genetic engineering approaches, one of which is genome editing. The application of genome editing with the Clustered Regularly Interspaced Short Palindromic Repeats (CRISPR) method to increase the "browning" of white adipose tissue has been widely used in the treatment of type 2 diabetes patients [5]. CRISPR/Cas9 is one of the methods being developed in the genome editing approach. CRISPR technology allows researchers to alter DNA sequences and modify gene function. This technology has the potential to correct genetic disorders, treat, and prevent the spread of certain diseases. Cas9 is an enzyme that acts as a molecular scissors capable of cutting DNA molecules. CRISPR technology is adapted from the natural defense mechanism of bacteria and archaea (domain of unicellular microorganisms). These organisms use CRISPR and Cas proteins (including Cas9) to thwart attack by viruses or other antigens. It does this by cutting and degrading the antigenic DNA molecule.

The success of CRISPR was carried out by molecular confirmation of related genes and single cell regeneration on selection medium to obtain cell generation with complete editing. The use of the right medium for each cell type is important, as it relates to optimal conditions for cell growth under in vitro conditions. Growth medium for fibroblast, myoblast and macrophage cells has not been reported. This paper will provide information on medium optimization for the three cell types.

\section{MATERIALS AND METHODS}

\subsection{Model and ethical clearance}

The study was conducted using fibroblast NIH3T3, macrophage RAW, and myoblast $\mathrm{C} 12 \mathrm{C} 2$ kindly provided by Prof. Tzhou Chi Huang from the Department of Food and Science, National Pingtung University Science and Technology. The study was conducted after receiving ethical clearance from the ethical committee Faculty of Medicine, Public Health, and Nursing Universitas Gadjah Mada (Ref No: KE/FK/0868/EC/2019).

\subsection{Medium Preparation}

Liquid medium was made by dissolving solid medium into $1 \mathrm{~L}$ of sterile aquabidest, then added $2.2 \mathrm{~g}$ of $\mathrm{NaHCO} 3$ and adjusted the $\mathrm{pH}$ by adding $1 \mathrm{~N} \mathrm{NaOH}$ or 1 $\mathrm{N} \mathrm{HCl}$. The medium was filtered with a 0.2 micron filter and accommodated in stock bottles (Duran $1000 \mathrm{~mL}$ ) at $4^{\circ} \mathrm{C}$. A total of $10 \mathrm{~mL}$ of fetal bovine serum and $1 \mathrm{~mL}$ of penicillin-streptomycin which had been diluted at room temperature were put into a new $100 \mathrm{~mL}$ Duran vial. The previously prepared liquid medium was added to the
Duran bottle until the volume reached $100 \mathrm{~mL}$. The entire process of making the medium was carried out aseptically in the laminar air flow.

\subsection{Cell Planting and Harvesting}

Cell harvest was carried out after the cells were $80 \%$ confluent. Cells were taken from the incubator and the medium was removed using a sterile micropipette or Pasteur pipette. Cells were then rinsed twice with 0.5 volume of phosphate buffer saline. Trypsin-EDTA 3\% was added evenly to the entire cell surface and incubated for 3 minutes in the incubator. After incubation, $5 \mathrm{~mL}$ of media was added to inactivate trypsin. Cell conditions were observed under a microscope. If there are clustered cells, then resuspension is carried out. The released cells were transferred one by one into a new sterile conical tube.

\subsection{Modified medium induction treatment}

Cells were induced with various concentrations of glucose and natrium. For cells grown on low-glucose medium, glucose induction was given of $10,15,20,25,30,35$ and $40 \mathrm{mmol} / \mathrm{L}$ and a sodium induction of $127,157,187,217$, 247, 277 and $307 \mathrm{mmol} / \mathrm{L}$. Meanwhile, for high-glucose medium, glucose induction of $40,43,45,46,47,50,53$, and $55 \mathrm{mmol} / \mathrm{L}$ and sodium of $131,161,191,221,251$, 281 and $311 \mathrm{mmol} / \mathrm{L}$

\subsection{MTT Assay}

Cell suspension in PRF RPMI 1640 medium as much as $100 \mathrm{~L}$ (density $1.5 \times 10^{4}$ cells/well) was put into a 96 well plate and incubated for 24 hours in a 5\% CO2 incubator. Then, the test solution was added in various concentration series for 3 replications. Plates were incubated in a 5\% $\mathrm{CO} 2$ incubator for 24 hours at $37^{\circ} \mathrm{C}$. At the end of incubation, the medium in each well was removed and washed with PBS, then $100 \mathrm{~L}$ of new medium and $10 \mathrm{~L}$ of $0.5 \%$ MTT were added. The plate was incubated again for 2.5 hours at $37^{\circ} \mathrm{C}$. Live cells will react with MTT to form purple formazan. Formazan was dissolved in SDS solution, then incubated for 12 hours at room temperature. The absorption was read with the ELISA Reader at a wavelength of $595 \mathrm{~nm}$ [6].

\subsection{Statistical analysis}

The data were presented as mean \pm standard deviation (SD). The results of the MTT assay were then tested statistically using the ANOVA test.

\section{RESULT AND DISCUSSION}

\subsection{Fibroblast Cell}

Fibroblast cells are one of the most common types of cells found in connective tissue components. These cells function to synthesize several components of the extracellular matrix such as reticular, elastin and collagen, as well as several types of anionic macromolecules such 
as glycosaminoglycans and proteoglycans. These components can promote cell attachment to the substrate. These fibroblast cells also function to secrete growth factors and cytokinin substances that can carry out cell proliferation and inhibit the process of cell differentiation [7]. These cells are commonly used to study metabolic syndrome disorders because their functions are closely related to the body's metabolic processes. The right medium is needed for optimal growth of fibroblast cells in evaluating their performance in environmental conditions high in glucose and natrium which are assumed to be conditions for the occurrence of metabolic syndrome. The following are the results of the optimization of glucose and sodium levels in the medium for fibroblast cells (Figure 1).

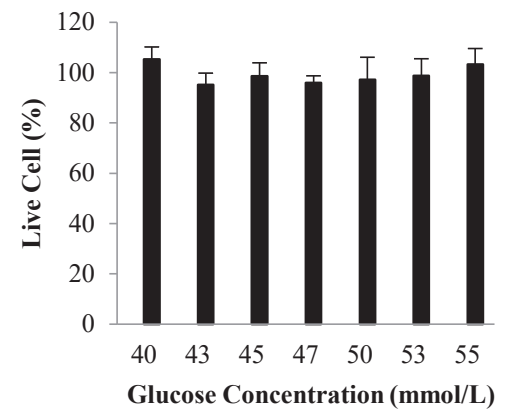

(a)

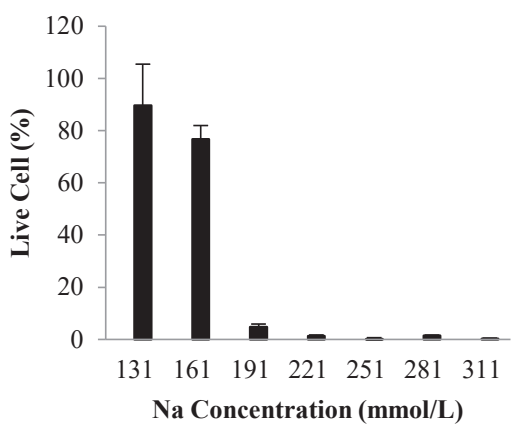

(b)

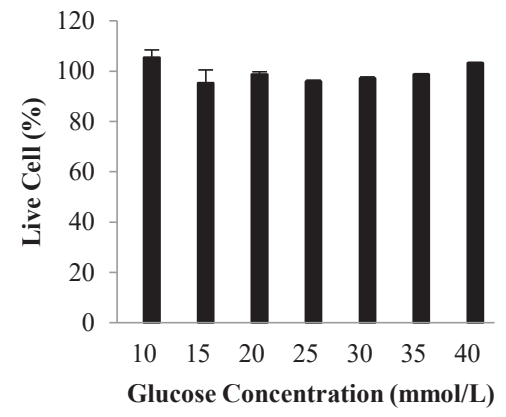

(c)

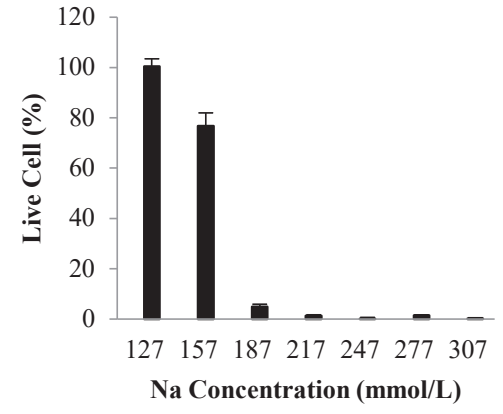

(d)

Fig. 1. Percentage of viable fibroblast cells on high-glucose medium treated with (a) high glucose and (b) high natrium treatment, and on low-glucose medium with (c) high glucose and (d) high natrium treatment.

In the high-glucose and low-glucose medium, glucose concentrations of $10-55 \mathrm{mmol} / \mathrm{L}$ did not give a significantly different effect on the growth of fibroblast cells. Fibroblast cells were still able to grow at the highest concentration of $55 \mathrm{mmol} / \mathrm{L}$ glucose and the lowest concentration of $10 \mathrm{mmol} / \mathrm{L}$. Meanwhile, in the medium high-glucose sodium induction treatment, fibroblast cells were only able to survive at a medium sodium concentration of $131 \mathrm{mmol} / \mathrm{L}$, and decreased at a concentration of $161 \mathrm{mmol} / \mathrm{L}$, while at $191 \mathrm{mmol} / \mathrm{L}$ the fibroblast cells were unable to grow properly, and only left $4 \%$ are still able to survive. In low-glucose medium, fibroblast cells were only able to survive at a sodium concentration of $127 \mathrm{mmol} / \mathrm{L}$, and decreased at a concentration of $157 \mathrm{mmol} / \mathrm{L}$, meanwhile at $187 \mathrm{mmol} / \mathrm{L}$ fibroblast cells were unable to grow properly, and only $5 \%$ were still able to grow.

High-glucose levels can inhibit the growth of fibroblast cells, according to Xuan et al., 2014, medium glucose levels of $90 \mathrm{mM}$ can interfere with the proliferation process of fibroblast cells and also affect their ability to migrate. However, the glucose concentration in DMEM high-glucose medium of $5.5 \mathrm{mM}$ did not affect the process of fibroblast cell proliferation [8]. In this study, it was proved that fibroblast cells induced by the addition of glucose content up to $50 \mathrm{mM}$ were still unable to inhibit the proliferation of fibroblast cells. The use of high-glucose medium, as well as medium glucose induction up to $50 \mathrm{mM}$ is still safe and good to use in inducing the growth and proliferation of fibroblast cells. Meanwhile, increasing the concentration of $\mathrm{NaCl}$ in a high medium could inhibit the differentiation of newly isolated human monocytes into fibroblast-like cells called fibrocytes. $\mathrm{NaCl}$ affects monocytes directly during their adhesion. Potassium chloride and sodium nitrate also potentiate the differentiation of fibrocytes. High levels of extracellular $\mathrm{NaCl}$ cause inhibition of the differentiation of fibrocytes by $95 \%$ [9]. In this study, the natrium content that can be tolerated by fibroblast cells is equal to 127 and $131 \mathrm{mmol} / \mathrm{L}$ natrium in both media, the higher the natrium content, the lower the viability of fibroblast cells, this is 
possible due to the failure of fibroblast cell proliferation due to disruption of cell membrane stability due to high natrium.

\subsection{Myoblast Cell}

Myoblast cells (C2C12) are one of the cells that can be used as research indicators in terms of metabolic disorders. These cells are able to proliferate rapidly in medium with high serum levels. However, in low serum medium conditions, myoblasts will differentiate into myotubes. Single-nucleated myoblasts can later fuse to form multinucleated myotubes under conditions of low serum or starvation. $\mathrm{C} 2 \mathrm{C} 12$ cells are also frequently used to study myoblast, osteoblast, and myogenesis differentiation, to express various target proteins, and to explore mechanistic biochemical pathways [7].

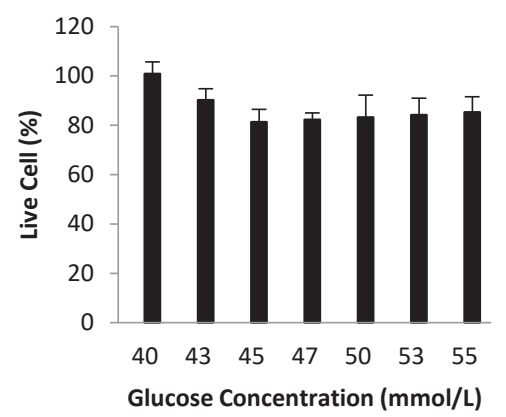

(a)

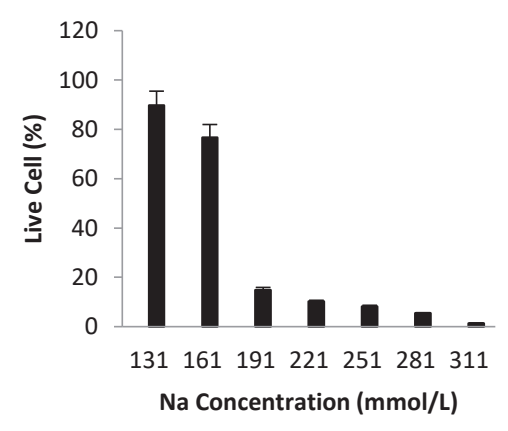

(b)



(c)

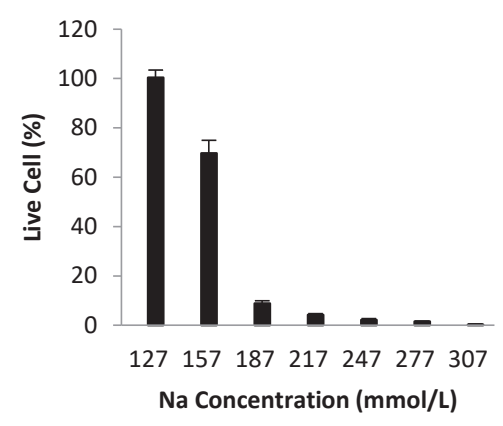

(d)

Fig. 2. Percentage of viable myoblast cells $\mathrm{C} 2 \mathrm{C} 12$ on highglucose medium when treated with (a) high glucose and (b) high natrium treatment, and on low-glucose medium with (c) high glucose and (d) high natrium treatment.

Myoblast cells were still able to grow at the highest concentration of $55 \mathrm{mmol} / \mathrm{L}$ glucose and the lowest concentration of $10 \mathrm{mmol} / \mathrm{L}$. Meanwhile, in the medium high-glucose sodium induction treatment, fibroblast cells were only able to survive at a medium sodium concentration of $131 \mathrm{mmol} / \mathrm{L}$, and decreased at a concentration of $161 \mathrm{mmol} / \mathrm{L}$, while at $191 \mathrm{mmol} / \mathrm{L}$ the fibroblast cells were unable to grow properly, and only left $4 \%$ are still able to survive. In low-glucose medium, fibroblast cells were only able to survive at a sodium concentration of $127 \mathrm{mmol} / \mathrm{L}$, and decreased at a concentration of 157, meanwhile at $187 \mathrm{mmol} / \mathrm{L}$ fibroblast cells were unable to grow properly, and only $5 \%$ were still able to grow.

\subsection{Macrophage Cell}

The accumulation of macrophages in adipose tissue of obese humans becomes very crucial because it is a molecular agent that causes inflammation in obesity. Activated macrophages in obese individuals can secrete various inflammatory cytokines and chemokines that interfere with insulin signaling. The increase in free fatty acids as occurs in obesity has been reported to induce inflammation of mononuclear cells [10]. In addition insulin resistance throughout the body is closely related to increased expression of macrophage cells. Insulin resistance is a key factor in the occurrence of metabolic syndrome in the body, which is a trigger for type 2 diabetes mellitus (DMT2) [11][12]. Therefore, macrophage cells are one of the appropriate cell models to study the process of metabolic syndrome and engineering its treatment. Optimal growing conditions for these cells are needed in order to obtain good evaluation results. The results of the optimization of macrophage cell growth medium in low and high glucose medium with the addition of glucose and sodium concentrations in the medium can be seen in Figure 3. 


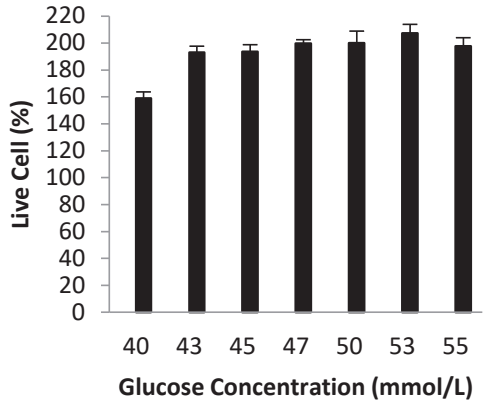

(a)

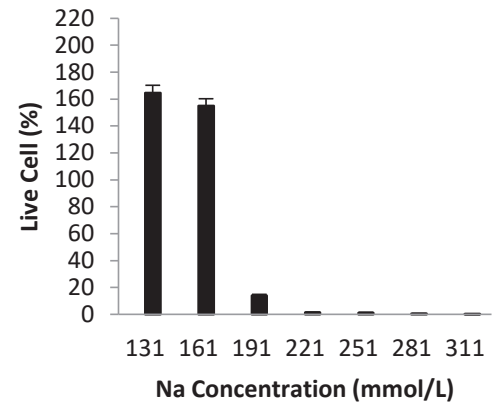

(b)

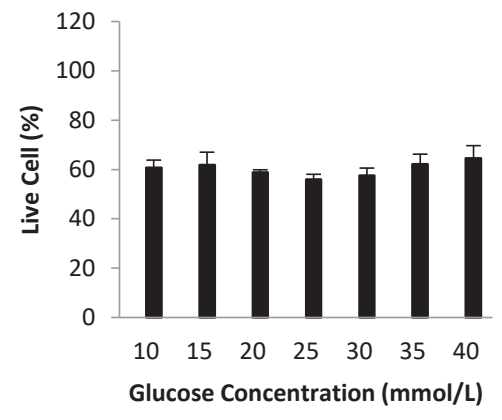

(c)

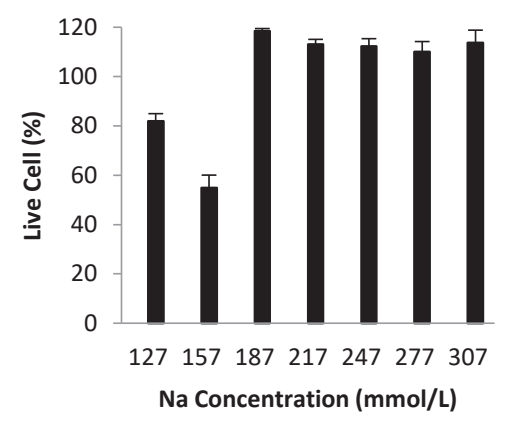

(d)

Fig. 3. Percentage of viable Macrophage cells RAW on High Glucose medium when treated with (a) high glucose and (b) high natrium treatment, and on Low Glucose medium with high glucose (c) and high natrium (d) treatment.
In the medium of high-glucose and low-glucose, glucose concentrations of $40-55 \mathrm{mmol} / \mathrm{L}$ did not give a significantly different effect on the growth of macrophage cells. Macrophage cells were still able to grow at the highest concentration of $55 \mathrm{mmol} / \mathrm{L}$ glucose. In lowglucose medium, there were significant differences in the treatment of $10-40 \mathrm{mmol} / \mathrm{L}$. Macrophage cells can grow well on low-glucose medium induced with various concentrations of sodium. Macrophage cells were able to grow in low-glucose medium with a concentration of 127 $-307 \mathrm{mmol} / \mathrm{L}$.

Microphages grown in high-glucose conditions can enhance immunomodulatory effects resulting in diabetic complications, such as diabetic neuropathy, but also conditions such as delayed wound healing, obesity, cardiovascular complications, or insulin resistance. In glucose levels that are too high, macrophage cells are still able to survive and live well. In high-glucose medium, macrophages can actually actively express certain genes in response to extreme high-glucose environmental conditions [13]. In this study, macrophages grown in high-glucose medium were able to grow well to medium high glucose content. However, in low-glucose medium the growth of macrophage cells was inhibited and did not grow optimally.

\section{CONCLUSION}

The results showed that in macrophage culture, the administration of variations in glucose concentration in low-glucose medium gave a significantly different percentage of live cells between treatments, while the treatment with variations in glucose concentration in macrophages in high-glucose medium and fibroblasts in high- and low-glucose medium did not show any difference in percentage of live cells. In the treatment of various concentrations of natrium, macrophages and fibroblasts on high- and low-glucose medium all showed significantly different percentages of living cells. Therefore, DMEM low-glucose medium is suitable as a medium for the treatment of high glucose and natrium induction in macrophage cells, but is not suitable for fibroblast and myoblast cells.

\section{Acknowledgement}

The authors would like to acknowledge the contribution of Ms. R.A. Wijayaningsih and Ms. Moza (Department of Pharmacology and Therapy, Faculty of Medicine) for their technical assistance. The authors also thank PDUPT Ministry of Education, Culture, Research and Technology/Universitas Gadjah Mada, Indonesia for providing research funding.

\section{References}

1. K. G. M. M. Alberti, P. Zimmet, J. Shaw. The metabolic syndrome - a new worldwide definition. The Lancet. 366(9491):1059-1062. (2005) 
2. K. G. M. M. Albert, R. H. Eckel, S. M. Grundy, P. Z. Zimmet, J. I. Cleeman, K. A. Donato, et al. Harmonizing the metabolic syndrome: a joint interim statement of the international diabetes federation task force on epidemiology and prevention. Circulation. 120(16):1640-1645. (2009)

3. S. Kachroo, S. J. T. Gowder. Gene therapy: An overview. Gene Technology. 5(1):1-14. (2016)

4. S. Mira. Human gene therapy: a brief overview of the genetic revolution. Journal of the Association of Physicians of India. 61:41-47. (2013)

5. J. A. Doudna. The promise and challenge of therapeutic genome editing. Nature. 578 (7794): 229-236. (2020)

6. L. Benov. Effect of growth media on the MTT colorimetric assay in bacteria. PLoS One. 14(8):18. (2019)

7. D.K. McMahon, P.A. Anderson, R. Nassar, J.B. Bunting, Z. Saba, A.E. Oakeley, N.N. Malouf. C2C12 cells: biophysical, biochemical, and immunocytochemical properties. American Journal of Physiology. 266(6 Pt 1):C1795-802. (1994)

8. Y. H. Xuan, B. B. Huang, H. S. Tian, L. S. Chi, Y. M. Duan. High-Glucose Inhibits Human Fibroblast Cell Migration in Wound Healing via Repression of bFGF-Regulating JNK Phosphorylation. PLoS One. 9(9):e108182. (2014)

9. N. Cox, D. Pilling, R. H. Gomer. $\mathrm{NaCl}$ potentiates human fibrocyte differentiation. PLoS One. 7(9):e45674. (2012)

10. P. Jiao, Q. Chen, S. Shah, J. Du, B. Tao, I. Tzameli, et al. Obesity-Related Upregulation of Monocyte Chemotactic Factors in Adipocytes. Diabetes. 58:104-115. (2009)

11. M. Qatanani, M. A. Lazar. Mechanisms of obesityassociated insulin resistance: many choices on the menu. Genes \& Development. 21:1443-1445. (2007)

12. J. Westerbacka, A. Cornér, M. Kolak, J. Makkonen, U. Turpeinen, A. Hamsten, et al. Insulin regulation of MCP-1 in human adipose tissue of obese and lean women. American Journal of Physiology Endocrinology and Metabolism. 294: 841-845. (2008)

13. R. Grosick, P. A. Alvarado-Vazquez, A. R. Messersmith, A. Romero-Sandoval. High glucose induces a priming effect in macrophages and exacerbates the production of pro-inflammatory cytokines after a challenge. Journal of Pain Research. 11:1769-1778. (2018) 